\title{
The Impacts of Increased Heat and Precipitation on Plant Phenology and Demography in Pacific Northwest Prairies
}

\author{
Ben Avis, Allie Ludden, Hunter Mackin, Andreas Martinez, Sean Petitt, \\ Elizabeth Porter, Emma Rasmussen, and Miles Steele*
}

\begin{abstract}
This study seeks to understand the implications that projected climate change will have on the phenology of seven prairie grass and forb species, such as disruptions in species interactions and native biodiversity loss. Data were collected at Willow Creek, an upland prairie in the city of Eugene. To assess the possible effects of climate change on plant survival rate and vigor, the experiment was designed to manipulate temperature and precipitation with four treatments (control, drought, heat, heat plus precipitation), and to measure the phenological and reproductive variables of the planted focal species. Experimental parameters were consistent with average predictions for changes in temperature and precipitation for the area. Phenological, demographic, and normalized difference vegetation index (NDVI) data were collected over an eight-week period. This study found warming treatments advance phenology for the forb species Plectritis congesta and Sidalcea malviflora. In addition, the grass species Festuca roemeri was found to have higher spikelet abundance in drought and control treatments, but no significant change to phenology. These results indicate that as temperatures rise with climate change, plant phenologies may shift, potentially reducing the reproductive fitness of certain plants.
\end{abstract}

\section{INTRODUCTION}

The current global accumulation of greenhouse gases is higher today than it has been in the last $~ 800,000$ years (NOAA, 2018). Accompanying the current increase in greenhouse gas

* Through the Environmental Leadership Program (ELP) within the Environmental Studies Program, eight undergraduate students prepared, performed, and completed a study over the course of two terms, with some work into the summer. In the first term, most of the background information necessary was learned, methods were developed, and a lengthy monitoring proposal was produced. In the second term, all the data was collected and analyzed and the results were discussed. Finally, all the work was compiled into a final report, which was presented at the 2018 ELP symposium. Now it is being put forth for a broader audience. From hardly knowing each other in the beginning, the eight students grew into a tight-knit team, with many long nights of work and many long laughs. The Climate and Phenology Team hopes people find their project as interesting as they did, and if there any questions, emails are encouraged. They can be reached at huntecmackin@gmail.com, and their faculty sponsors, Laura McCullough and Peg Boulay, can be reached respectively at Imccull2@uoregon.edu and boulay@uoregon.edu. 
emissions, global precipitation and air temperature increased by $1.37 \mathrm{~mm} / \mathrm{yr}$ and $0.024^{\circ} \mathrm{C} / \mathrm{yr}$ respectively between 1981 and 2000 (Tian et al., 2015). This warming trend is expected to continue, with mean global air temperature forecasted to rise another $1.8-4.08^{\circ} \mathrm{C}$ by 2100 (Dunne, Harte, \& Taylor, 2003). Considering that newer predictions anticipate a rise of 1.67 $3.89^{\circ} \mathrm{C}$ by 2050 and $2.78-6.11^{\circ} \mathrm{C}$ on average by 2080 in Oregon, understanding the impacts of warming on local plant phenology, the study of seasonal and cyclic natural phenomena, has never been more imperative (Oregon Climate Assessment Report, 2017; Calado \& Leal, 2012). There is significant evidence that species' ranges, or geographical distributions, have been altered by climate change; if this trend continues, it could have substantial implications for native vegetation (Pfeifer-Meister et al., 2013; Bachelet et al., 2011).

Over the past twenty years, the impacts of climate warming on natural systems have been recorded across the globe using phenological data (Khanduri, 2008). It has been determined that autumn and spring phenologies have shifted, causing growing seasons to start later (Ibanez et al., 2010). Researchers have concluded that for many plant species, higher spring temperatures affect phenology by advancing the rate at which plants come to reproductive maturity in the spring; however, this differs depending on the plant species (Fitter, Fitter, Harrels, \& Willamson, 2002). Despite this variation, flowering rates have advanced up to four days per degree Celsius on average, when plants are subjected to higher temperatures shortly before flowering (Fitter et al., 2002). When warming occurs four to six months prior to flowering, this temperature change delays phenology (Fitter et al., 2002).

The Pacific Northwest is located within a Mediterranean climate zone, which has hot, dry summers, and wet, mild winters. The drier summers mean climate change effects in the area are expected to be even more drastic than in other locations. The projected increase in temperature could affect plant community composition, decrease native diversity, and increase total cover, especially in an area where there has been significant habitat fragmentation and proliferation of invasive species (Pfeifer-Meister et al., 2013). Thus, researchers predict that the loss of biodiversity will be greater here than in other types of biomes (Pfeifer-Meister et al., 2013).

Many experiments have been done to determine the future of prairie productivity under different climate change projections. Through these experiments, researchers have concluded that, in addition to a decrease in biodiversity, warming has a high likelihood of causing shifts in vegetation ranges and community populations (Bachelet et al., 2011). In a 2013 study examining how increased temperatures could affect vegetation ranges, added heat improved the recruitment, or the successful reproduction, of species that were moved north of their current range, indicating that species might be able to thrive if they disperse northwards as conditions change (PfeiferMeister et al., 2013). However, such areas are often already occupied by other species, which might increase competition for space and nutrients.

In a warming-induced study carried out by Whittington et al. (2015), flowering and senescence timing at the individual level also experienced significant shifts. For individuals, budding occurred approximately seven days earlier, and flowering onset approximately seven to eight days earlier, with the most significant effects occurring under increased warming conditions of $3^{\circ} \mathrm{C}$. 
Competition and phenological shifts like these may cause asynchronicities between plants and pollinators, which could result in a decline in the fitness of prairie ecosystems as temperatures continue to rise (Whittington et al., 2015).

In a study by Pfeifer-Meister et al. (2013), an increase in temperature was shown to reduce overall survivorship as southern species were moved northward. Interestingly, increased biomass and seed production were correlated with increased temperature and precipitation regardless of geographic distribution, both independently and together. Nutrient availability also increased with temperature, although this was likely an indirect effect of heating on the nutrients (PfeiferMeister et al., 2013). Overall, these positive effects were outweighed by the negative effects of lowered germination rates and survivorship. This suggests that climate change could hinder the ability of native plants to survive in their current ranges (Pfeifer-Meister et al., 2013).

With warmer temperatures, native plants may face the threat of competition from other plants, especially non-native annual grasses (Pfeifer-Meister et al., 2015). Under experimental conditions of warming, annual plant species began emerging earlier, and competed more heavily against perennial species. Among the three sites tested, the northernmost site had the lowest proportion of annuals, the central site had an intermediate proportion, and the southernmost site had the highest proportion (Pfeifer-Meister et al., 2015). Overall biodiversity also decreased over time under all treatments, with Simpson's index of diversity (which is a calculation of species richness and evenness) dropping, and species richness dropping even further (Pfeifer-Meister et al., 2015). In addition, invasive species tended to adapt the best to drought conditions, as they are more effective competitors for nitrogen (Pfeifer-Meister et al., 2015). The carbon content of the soil was also affected with an average loss of $40 \mathrm{Mg}$ ha-1 in soil carbon attributed to the invasion (PfeiferMeister et al., 2015).

By using the results from current experiments and analyzing phenological data from past studies, it is possible to get an even clearer look at the short- and long-term effects of climate change on plants within the scarce prairie regions of the Pacific Northwest. There is a prevailing sense that climate change will negatively impact plant phenology and cause species to shift their ranges, but further studies are needed to improve the understanding of the issue. The analysis of data collected from these studies could also help inform decisions pertaining to future restoration projects and policies.

There were three goals for our study: to recognize and interpret the impacts that varying "climate treatments" have on A) the phenology of several species, B) the overall greenness and biomass accumulation of species, and C) the reproductive fitness of species. Our hypotheses are as follows:

H1) Warming treatments (heat and heat plus precipitation) will result in an advancement in phenology of forbs and grasses. This is because prairie plants time their reproductive cycles in response to seasonal temperature changes.

H2) Using a normalized difference vegetation index (NDVI), warming treatments (heat and heat plus precipitation) will result in a higher amount 
of biomass as well as an earlier peak in biomass. This is expected from a larger/earlier nutrient uptake associated with warming.

H3) Drought treatments will result in a fewer number of total flowers/spikelets and flowering plants/plants with spikelets than that of the control treatments due to a reduction of soil moisture. This is expected due to reduced water availability for roots.

\section{METHODS}

\section{STUDY SITE}

The experiment took place at Willow Creek Preserve, which consists of 519 acres of protected native habitat located in West Eugene, Oregon. The preserve contains a wide variety of vegetative communities including upland prairie, wetland prairie, forested wetland, riparian forest, and oak woodland. The study site was located in an upland prairie on the southwest side of The Nature Conservancy's Willow Creek Preserve.

\section{EXPERIMENTAL DESIGN}

Four climatic manipulations were embedded throughout 20 numbered plots. Each plot was randomly assigned one of four climate treatments: drought $(-40 \%$ precipitation $)$, heat $\left(+2.5^{\circ} \mathrm{C}\right)$, heat plus precipitation, and control. Due to the decline in soil moisture caused by heating alone, heat plus precipitation treatments were included to ameliorate the effects of soil drying. In total, there were five replicate plots for each treatment. In order to ensure species location consistency, all plots were designed to be $3 \mathrm{~m}$ in diameter with PVC rings placed in each plot. Rings were arranged using an $\mathrm{x}, \mathrm{y}$ grid coordinate system that contained $8 \mathrm{PVC}$ rings for each of the 12 species per plot, with 25 seeds planted within each PVC ring. Species' positions were consistent at each plot, but a different ring was used each year. In each control plot, imitation wooden heaters were constructed to mimic the shading effect of the electrical equipment used in the heated plots.

\section{DATA COLLECTION}

From April 13 through May 25 of 2018, our team traveled to the Willow Creek site to make observations and record data pertaining to the 12 grass and forb species each Friday. We broke up into teams of two, and half of each team made observations while the other half recorded data gathered by the observer. We collected three categories of data: NDVI data, essentially a measure of greenness to calculate overall vegetative canopy cover, phenological data consisting of budding, flowering, and senescence, and demographic census data to assess overall plant reproduction.

NDVI data were gathered weekly by using a GeoSCOUT GLS-400, a handheld remote sensing device capable of measuring the canopy reflectance of vegetation in any lighting. The plots at Willow Creek were monitored in an identical way every week. Six measurements were taken at 
each plot per week, with each measurement taken at waist level and facing a different direction: northwest (starting location), west, southwest, southeast, east, and northeast.

The second weekly protocol was to collect phenological data for all present focal species. In order to maintain uniformity, every Friday at 11 a.m., each team systematically recorded data for all species. Because time of day can affect phenology, each week a new, randomly-selected starting plot was chosen. With one measurer and one recorder, team members worked together to collect data in all 20 plots, alternating roles between each plot. For forb species, the number of plants exhibiting flowers with visible reproductive organs were counted, as well as the total number of flowers in each plot. Additionally, we counted the total number of plants with buds showing petals and total number of buds in each plot. Data on the grasses were collected by counting the number of flowering stalks. For all focal species, the presence of senescence was noted. We also recorded any observations, variables, deviations from protocol, or other details that could have potentially affected experimental outcomes.

\section{DATA ANALYSIS}

There were a number of variables that measured the progress of phenology under different treatments. The variables, unlike the treatments, differed between grass and forb species. For native forb species, indicator variables consisted of the number of plants with buds, the number of buds per plot, the number of plants with flowers, and the number of flowers per plot. For native grass species, the indicator variables were the number of plants with spikelets and the number of flowering stalks per plot. The one common indicator was whether senescence was present or absent. This form of analysis showed first flowering, peak flowering times, and senescence timing for each climate treatment. Data analysis was not performed for the NDVI data collected on April 27 due to a data entry error.

The final analysis was conducted using the statistical software SPSS. Descriptive statistics and homogeneity of variance were checked first. Then, an analysis of variance, or ANOVA, was used to test the significance (standardized at the 5\% level) of each treatment on every phenological variable measured, for every species. If the ANOVA was significant, Tukey's post-hoc test, which identifies significant differences between means, was performed to identify which treatments were significantly different from each other. NDVI was also analyzed by treatment for each day data were collected using ANOVA and Tukey's test.

\section{RESULTS}

During the study period, we were able to measure variables for seven focal species, specifically five forbes and two grasses. The relevant forbs were Sidalcea malviflora, Plectritis congesta, Plagiobothrys nothofulvus, Achyrachaena mollis, and Collinsia grandiflora, and the relevant grasses were Festuca roemeri and Danthonia californica. 


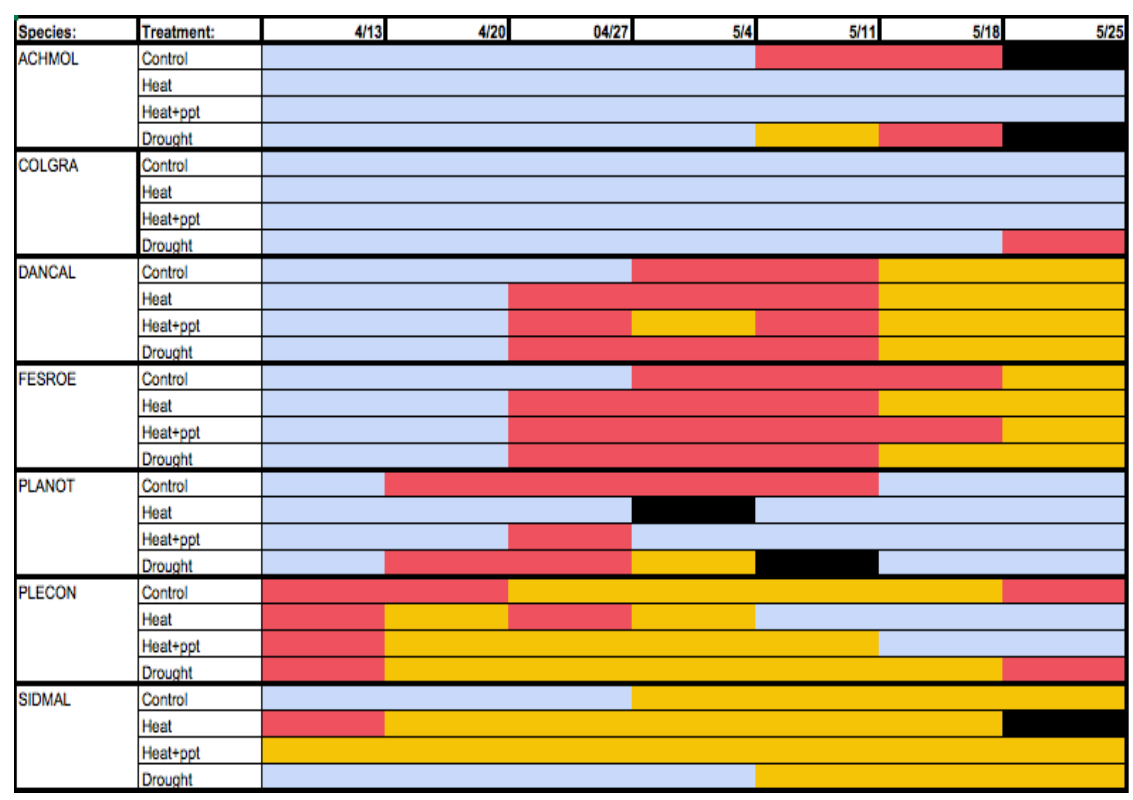

\begin{tabular}{|l|l|}
\hline Legend & \\
\hline & No flowers present \\
\hline & Flowers/ spiklets present \\
\hline & Senecence and Flowers/Spiklets present \\
\hline & Only senecent flowers/spikelets present \\
\hline
\end{tabular}

Figure 1: Timing of phenological markers across climate treatments for seven focal species (ACHMOL: Achyrachaena mollis, COLGRA: Collinsia grandiflora, DANCAL: Danthonia californica, FESROE: Festuca roemeri, PLANOT: Plagiobothrys nothofulvus, PLECON: Plectritis congesta, SIDMAL: Sidalcea malviflora)

\section{PHENOLOGY AMONG SPECIES}

Earlier flowering times were predicted for all species in response to warming, in both heat and heat plus precipitation treatments. However, only two species, $P$. congesta and $S$. malviflora, had significantly earlier flowering times. F. roemeri also exhibited a significant trend in spikelet abundance, with highest abundance in control and drought treatments. Most species' first flowering occurred in drought plots (Fig. 2). However, several species flowered first in the heat, heat and precipitation, and control conditions (Fig. 2). Control plots were the least eventful, with no senescence and only one peak flowering occurring first in this treatment (Fig. 2). First peak flowering was observed in all treatments (Fig. 2). Two species, P. congesta and S. malviflora, were already flowering on the first day of data collection (Fig. 1). 
Species Response to Climate Treatments

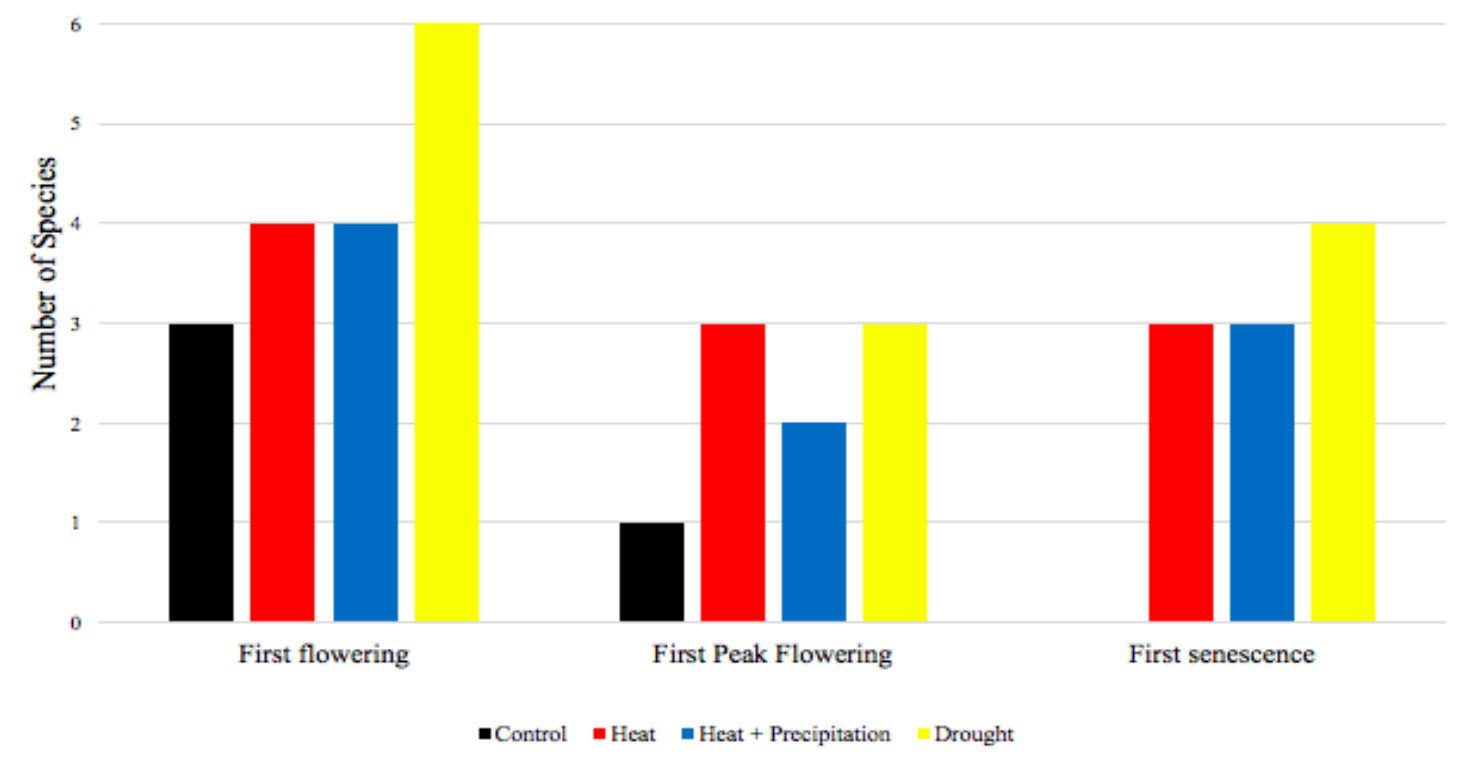

Figure 2: The treatment where first flowering, first peak flowering, and first senescence occurred was totaled across species. If a phenological event occurred first in more than one treatment, all applicable treatments were tallied.

The majority of species observed had the highest peak of average plants with flowers in the drought and control treatments, with the exception of $S$. malviflora, where heat and heat plus precipitation produced the highest average of plants with flowers. The abundance of plants with flowers tended to aggregate between drought and control treatments, and heat and heat plus precipitation treatments, with the exception of D. californica (Fig. 3). For A. mollis, only drought and control treatments had flowering plants during data collection. 

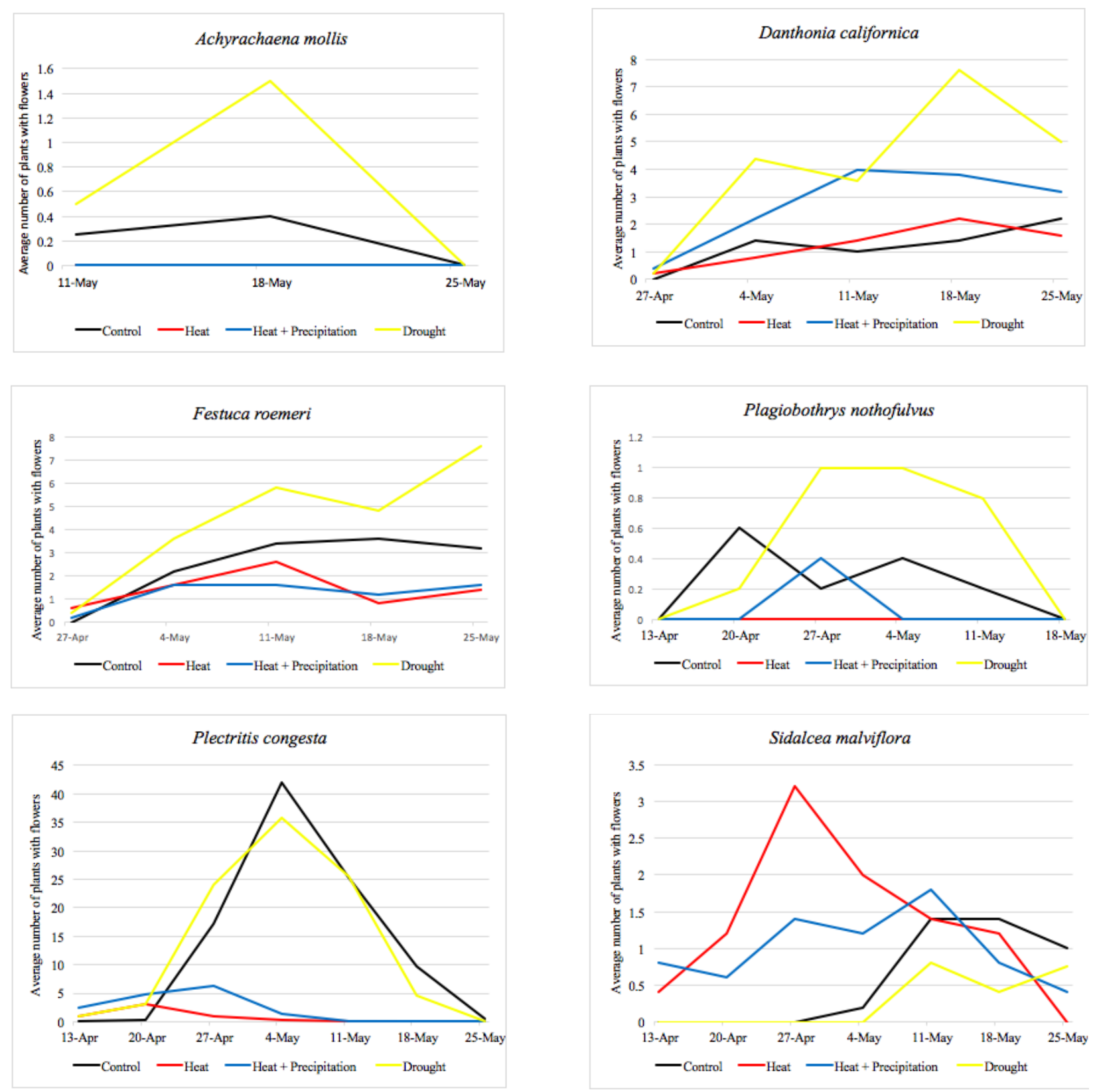

Figure 3: Average number of plants with flowers per treatment over time for species: Achyrachaena mollis, Danthonia californica, Festuca roemeri, Plagiobothrys nothofulvus, Plectritis congesta, Sidalcea malviflora. 


\section{SPECIES-SPECIFIC PHENOLOGY}

\section{PLECTRITIS CONGESTA}

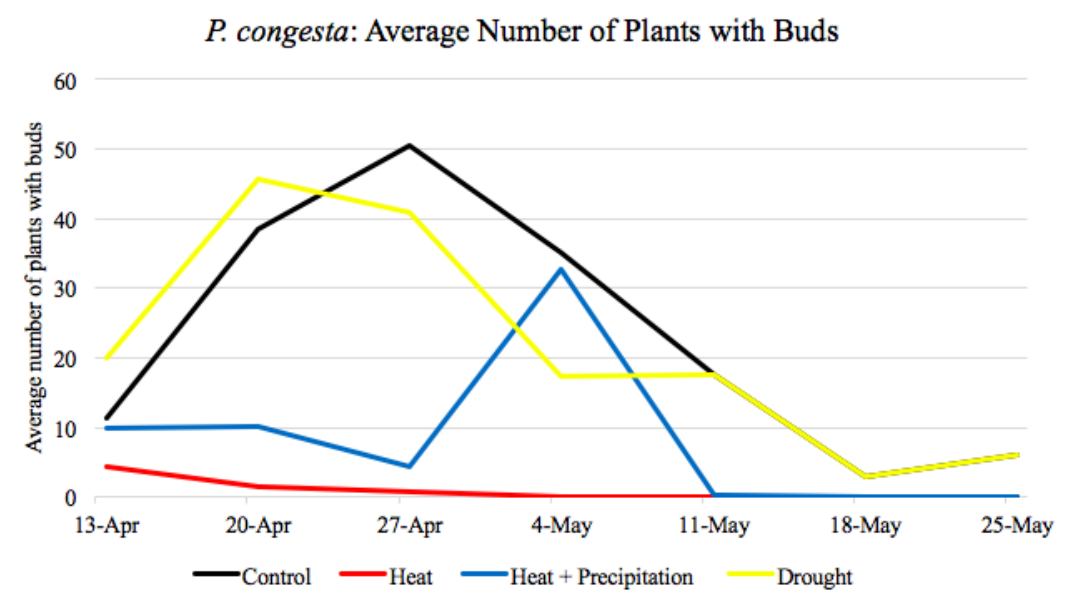

Figure 4: Number of Plectritis congesta with buds present across the different treatments.

The average number of plants with buds of $P$. congesta peaked earliest in the heat treatment plots on April 13 (Fig. 4). The peak average number of plants with buds in drought occurred the following week on April 20, and control followed the week after on April 27 (Fig. 4). For the heat plus precipitation treatment, the peak average number of plants with buds did not follow the same bell curve trend. Instead, it experienced a decrease in the average number of plants with buds between April 20 and April 27, then reached its peak the latest of all treatments, on May 4 (Fig. 4).

For $P$. congesta, the average number of plants with buds yielded significant differences between drought and heat on April $27(p=0.002)$, May $4(p<0.001)$, and May $11(p=0.031)$ (Fig. 5). Between drought and heat plus precipitation, significant difference occurred on April 27 ( $p=0.018)$, May $4(p<0.001)$, and May $11(p=0.032)$ (Fig. 4$)$. The difference between control and heat plus precipitation was significant on May $4(p<0.001)$, May $11(p=0.034)$, and May 18 $(p=0.003)$. Control and heat were significantly different on April $27(p=0.033)$, May $4(p<$ o.001), May $11(p=0.032)$, and May 18 ( $p=0.003)$.

Similar to the average of plants with buds, heated plots experienced the earliest phenology, with a peak in the average of plants with flowers occurring on April 20 (Fig. 3). The heat plus precipitation treatment reached the peak of average plants with flowers on April 27, followed by a steady decline. Both drought and control plots experienced a peak in average plants with flowers on May 4. Senescence in P. Congesta was first recorded on April 20 in heat, drought, and heat plus precipitation treatments.

SIDALCEA MALVIFLORA 
S. malviflora: Average Number of Plants with Buds

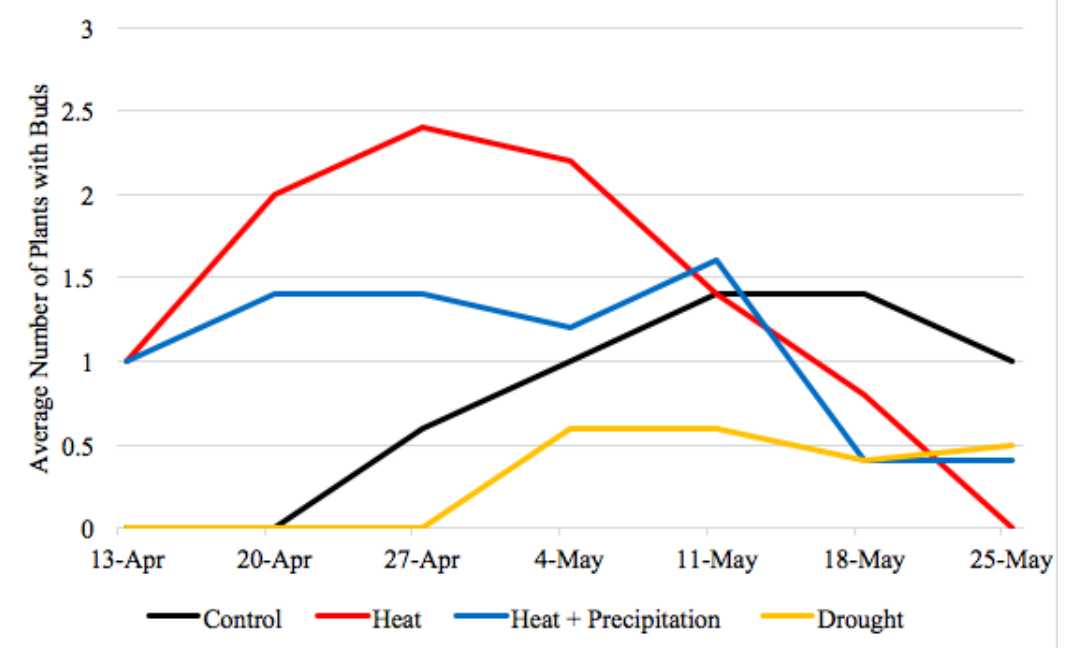

Figure 5: Number of Sidalcea malviflora with buds present across the different treatments.

S. malviflora exhibited advanced phenology in the heat treatments compared to the control and drought treatments. The peak of average number of plants with buds occurred earliest in the heat treatment on April 27, then on May 4 for drought, May 11 for heat plus precipitation, and between May 11 and 18 for control (Fig. 5). For the average number of plants with buds, significant differences were found on April 20 between control and heat $(p=0.015)$ and between drought and heat ( $p=0.015$ ) (Fig. 5).

This trend continued for the average number of plants with flowers, with heat peaking on April 27, while control and drought both peaked later on May 11 (Fig. 5). Heat plus precipitation had an overall maximum average number of plants with flowers on May 11, but a secondary peak was observed on April 27 (Fig. 5). Senescence across all treatments was first observed in heat plus precipitation on April 13, and in heat on April 20 (Fig. 1). Both control and drought experienced later first senescences on May 4 and May 11 respectively (Fig. 1). Heat was the only treatment to have full senescence during data collection, occurring on May 25 (Fig. 1).

For the average number of plants with flowers, $S$. malviflora was significantly different between control and heat ( $p=0.015)$, and drought and heat $(p=0.015)$ on April 27 (Fig. 3).

\section{FESTUCA ROEMERI}

F. roemeri had more average plants with spikelets in drought and control treatments than in heat plus precipitation and heat treatments across the entire data collection period (Fig. 3). Drought and heat plus precipitation treatments were found to be significantly different on May 11 ( $\mathrm{p}=0.021)$, May 18 ( $\mathrm{p}=0.021)$, and May 25 ( $\mathrm{p=0.015)}$ (Fig. 3). Drought and heat treatments were significantly different on May 18 ( $\mathrm{p}=0.005)$ and May 25 ( $\mathrm{p}=0.011)$ (Fig. 3). Total spikelets per plot for $F$. roemeri was significantly different on May 18 between drought and heat (0.033) and between drought and heat plus precipitation ( $\mathrm{p}=0.016)$ (Fig. 3). Spikelets for F. roemeri were first found on April 27 in heat, heat plus precipitation, and drought treatments (Fig. 1). Senescence 
was first noted on May 18 in both heat and drought treatments (Fig. 1). Phenology for control treatments followed a different trend, with spikelets occurring first on May 4 and senescence first noted May 25 (Fig. 1).

\section{ACHYRACHAENA MOLLIS, DANTHONIA CALIFORNICA, PLAGIOBOTHRYS NOTHOFULVUS}

A. mollis only flowered in control and drought treatments during data collection. For average plants with flowers, $A$. mollis yielded significant differences on May 18 between drought and heat treatments $(\mathrm{p}=0.038)$ and between drought and heat plus precipitation treatments $(\mathrm{p}=0.038)$ (Fig. 3). P. nothofulvus also flowered earlier in control and heat, with first peak flowering occurring in control (Fig. 3). D. californica was the only species where control and drought did not follow similar trends; instead, drought and heat plus precipitation treatments were similar, with both exhibiting the most flowering plants during the data collection period (Fig. 3).

\section{NORMALIZED DIFFERENCE VEGETATION INDEX}

Across all treatments, plot productivity was measured by NDVI throughout the eight weeks. Through this data, no significant interaction between the average NDVI value and type of climate treatment was observed. Differences were observed, but these were not significant for the alpha level selected. However, the heat and heat plus precipitation treatments experienced an earlier peak in NDVI than the drought and control treatments.

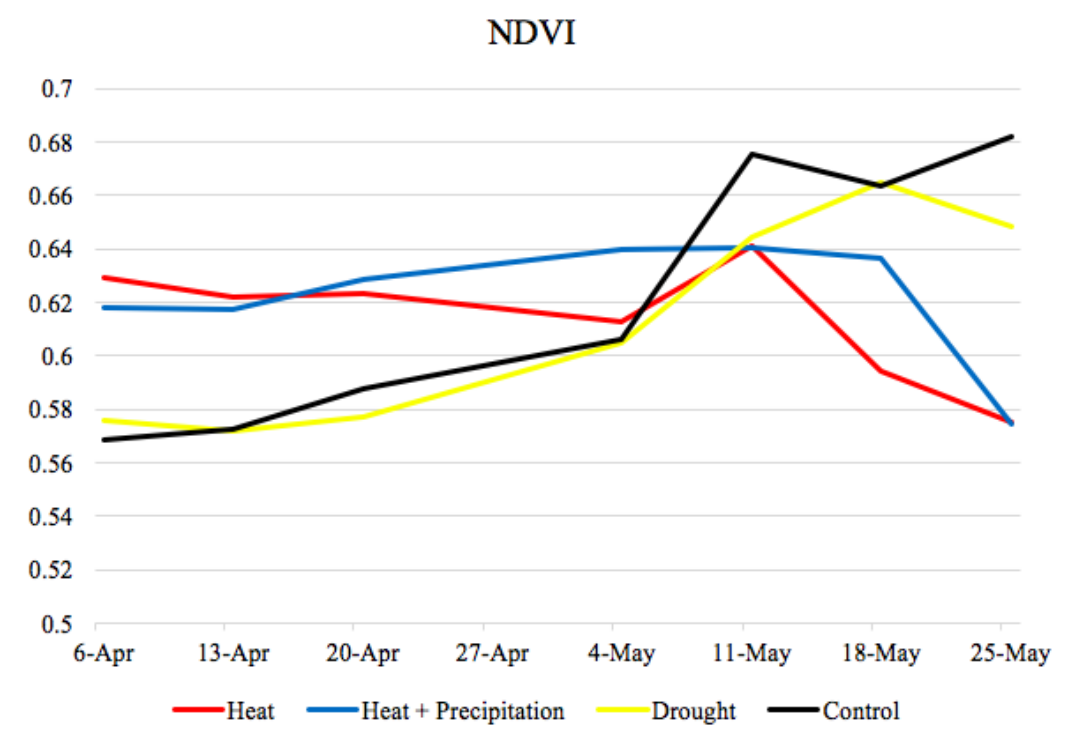

Figure 6: Averaged normalized difference vegetation index for the four treatments over time.

\section{DISCUSSION}




\section{SIGNIFICANCE}

P. congesta had a peak average flowering time under the heat treatment on April 13 (Fig. 4). This indicates that the true peak in the average number of plants with buds either occurred before data collection or that the species didn't germinate much at all within the heat treatment. The average number of plants with buds in heat and heat plus precipitation treatments proved significantly lower than drought and control treatments on multiple dates: April 27 and May 4, May 11 for heat only, and April 27 and May 4 for heat plus precipitation only. Control and drought treatments appeared to foster higher numbers and rates of reproduction of this species the most frequently, though not for every date. This indicates that rising temperatures may reduce the fitness of $P$. congesta.

F. roemeri generally proved much more plentiful and reproductive within the drought and control treatments than within the heat and heat plus precipitation treatments. Drought treatments produced on average the most plants with spikelets, while heat treatments generally produced the least. While drought conditions don't appear to be a threat to the fitness of this species, warming conditions do appear to be a threat.

Hypothesis 1 (H1), which predicted that warming treatments would advance the phenology of forbs and grasses, appeared to hold for at least one forb, S. malviflora, with warming treatments advancing its phenology relative to control and drought treatments (Fig. 1). However, drought conditions appeared to advance phenology as quickly or more quickly than any other treatment for every other focal species (Fig. 1). First flowering occurred in four of the focal species for both heat and heat plus precipitation treatments, with only three observed in control. Yet drought had the highest, with the first flowering of six species observed within respective plots. The second hypothesis (H2), which stated that heating treatments would result in a higher amount and earlier peak in biomass, did not have any significant evidence indicating it should be rejected or failed to be rejected. There was no significant difference in timing of peak biomass. The third hypothesis $\left(\mathrm{H}_{3}\right)$, which stated that drought treatments would result in the lowest number of flowers/spikelets and flowering plants/plants with spikelets, was rejected, especially for grasses, where drought treatments generally produced the most spikelets.

\section{PLANTS AND POLLINATORS}

Pollinators play a pivotal role in plant reproduction, and the trends observed under heat treatments could disrupt this role. There is evidence that suggests climate change does not alter the duration of flowering or fruiting (Price \& Waser, 1998), yet in our study, abbreviated flowering times were observed under heat treatments, perhaps most notably for $P$. congesta and $P$. nothofulvus (Fig. 4). The aforementioned research did find evidence that warming advances the timing of reproduction (Price \& Waser, 1998). Our experiment corroborates that finding, with first flowering and first senescence occurring earlier for more species in both heat and heat plus precipitation plots than control plots (Fig. 2). However, drought plots appeared to advance the phenology of the most plants across the board (Fig. 2). With phenology advanced in most focal species for every experimental treatment, it may be posited that pollinators, many of which 
coevolved with some focal species, could arrive late under future climate change scenarios. In turn, they might be absent during peak flowering times, which could reduce the fitness of both species.

\section{NORMALIZED DIFFERENCE VEGETATION INDEX}

NDVI had no statistically significant differences across treatments. As for any observable trend, the index appeared fairly the same for drought and control (Fig. 6). Additionally, heat seemed analogous to heat plus precipitation, apart from relatively large rises and falls in heated plots date to date in the latter half of the data collection period (Fig. 6). Throughout the study, similar effects were often observed between control and drought treatments, as well as between heat and heat plus precipitation treatments. This indicates that heat may be more affecting than precipitation for many species. Compared to heat and heat plus precipitation plots, control and drought plots had lower biomass at the start. However, by May 11, both had achieved higher NDVI values than heat and heat plus precipitation (Fig. 6). On May 25, control had the highest peak biomass, while heat and heat plus precipitation both had relatively low biomass, in addition to a much lower peak biomass overall (Fig. 6). This indicates that biomass may decline more quickly as summer progresses under future climate change, and may even be lower altogether. Consequently, ecosystems might be disrupted and lose a significant amount of life.

\section{INVASIVE SPECIES}

Invasive plant species create more competition for native plant species for vital resources, such as sunlight, water, and space. Should an invasive species come from a naturally warmer and/or drier climate, they would likely be better suited to exist in the conditions of projected climate change. This might significantly impair the survivability of smaller forbs, such as $P$. nothofulvus and $A$. mollis, which were never observed to grow under grass cover, likely due to getting shaded out.

\section{METHOD ERRORS}

The total number of $S$. malviflora plants may have been over-counted, as many plants that appeared to be spaced far away from each other turned out to be the same plant under closer examination. This fact was disseminated at the start of data collection, but errors could have occurred regardless, and may have given an upward bias to plants with buds and plants with flowers.

$P$. nothofulvus and A. mollis were very small and hard to find, often requiring data collectors to brush aside other plants and use magnifying glasses to determine whether they were present. While extra time was devoted to finding these plants and checking every relevant ring thoroughly, there still may have been plants that were missed, which may have biased all dependent variables downward. 
One drought plot was missed for A. mollis on May 18, and another drought plot was missed for S. malviflora on May 25. These were excluded from analysis, but certainly decreased the power of the analysis conducted for these species on both of these dates.

\section{CONCLUSION}

Our results showed that the warming treatments generally resulted in earlier senescence of plants and forbs. If this trend is upheld with predicted temperature increase, it could decrease length of flowering time and cause asynchronicities between local species and their pollinators, which could result in reduced fitness for both species. Since many native prairie species may be at risk of experiencing these detrimental effects, it is imperative that conservation efforts are made on existing prairies. In future studies, researchers could test the significance of flowering time and senescence in plant/pollinator interactions, now that there are evidenced differences across climate variations. This would provide us with a better idea of how prairie systems might be affected by climate variations. Further conversations are necessary to determine what steps must be taken in order to mitigate the effects climate change may have on endemic prairie systems. These may include the possibility of forced migration of species who will no longer be able to thrive at their current ranges. While our study has by no means determined what is necessary to the survival of prairie systems, we hope that our findings will benefit future studies and conversations.

\section{ACKNOWLEDGEMENTS}

NSF Macrosystems Biology Grant \#EF-1340847

Principle Investigators(Community Partners): Scott Bridgham, Bitty Roy, Laurel Pfeifer-Meister, Bart Johnson

Other Community Partners: Paul Reed, Aaron Nelson, and the rest of the HOPS team

Environmental Leadership Program: Peg Boulay, Laura McCullough

The Nature Conservancy

\section{REFERENCES}

Bachelet, D., Johnson, B. R., Bridgham, S. D., Dunn, P. V., Anderson, H. E., \& Rogers, B. M. (2011). Climate change impacts on western Pacific Northwest prairies and savannas. Northwest Science, 85(2), 411-429.

Boden, T., Marland G., \& Andres, R. (2017) Global, Regional, and National Fossil-Fuel CO2 Emissions. Carbon Dioxide Information Analysis Center, Oak Ridge National Laboratory, U.S. Department of Energy, Oak Ridge, Tenn., U.S.A. 
Buffington, K., Dugger, B., \& Thorne, K. (2018) Climate-related variation in plant peak biomass and growth phenology across Pacific Northwest tidal marshes. Estuarine, Coastal and Shelf Science, 202: 212-221.

Calado, R., \& Leal, M. C. (2015). Trophic Ecology of Benthic Marine Invertebrates with BiPhasic Life Cycles. Advances in Marine Biology,1-70. doi:10.1016/bs.amb.2015.07.001

Carey, J. C., Tang, J., Templer, P. H., Kroeger, K. D., Crowther, T. W., Burton, A. J., ... \& Jiang, L. (2016). Temperature response of soil respiration largely unaltered with experimental warming. Proceedings of the National Academy of Sciences, 113(48), 13797-13802.

Dalton, M. M., Dello, K. D., Hawkins, L., Mote, P. W., \& Rupp, D. E. (2017). The third Oregon climate assessment report. Oregon Climate Change Research Institute, College of Earth, Ocean, and Atmospheric Sciences, Oregon State University, Corvallis, Oregon.

Dalton, M., Mote, Philip W., Snover, Amy K., Pacific Northwest Climate Impacts Research Consortium, author, National Climate Assessment, \& Geological Survey, sponsoring body. (2013). Climate change in the Northwest : Implications for our landscapes, waters, and communities (National climate assessment regional technical input report series). Washington ; Covelo ; London: Island Press.

Dunne, J., Harte, J., \& Taylor, K. (2003) Subalpine flowering phenology responses to climate change: integrating experimental and gradient methods. Ecological Society of America, 73(1): 69-86.

Dwire, K. A., Mellmann-Brown, S., \& Gurrieri, J. T. (2017). Potential effects of climate change on riparian areas, wetlands, and groundwater-dependent ecosystems in the Blue Mountains, Oregon, USA. Climate Services.

Fitter, A., Fitter, R., Harris, I., \& Williamson, M. (2002) Relationships between First Flowering Date and Temperature in the Flora of a Locality in Central England. Functional Ecology, 9(1): 55-6o.

Hamman, S., Dunwiddie, P., Nuckols, J., \& McKinley, M. (2011) Fire as a Restoration Tool in Pacific Northwest Prairies and Oak Woodlands: Challenges, Successes, and Future Directions. Northwest Science, 85: 317-328.

Ibáñez, I., Primack, R., Miller-Rushing, A., Ellwood, E., Higuchi, H., Lee, S., Kobori, H., \& Silander, J. (2010) Forecasting phenology under global warming. Philosophical Transactions of the Royal Society B: Biological Sciences, 365(1555): 3247-3260.

Intergovernmental Panel on Climate Change (2007) Climate Change 2007: Impacts, Adaptation and Vulnerability. 22.

Johnson, B. (2015) A new model to simulate climate-change impacts on forest succession for local land management. Ecological Applications, 25(1): 226-242. 
Jung, I., \& Chang, H. (2011) Climate change impacts on spatial patterns in drought risk in the Willamette River Basin, Oregon, USA. Theoretical and Applied Climatology, 108(3-4): 355371.

Khanduri, V., Sharma, C., \& Singh, S. (2008) The effects of climate change on plant phenology. The Environmentalist, 28(2): 143-147.

Latta, G., Temesgen, H., Adams, D., \& Barrett, T. (2010) Analysis of potential impacts of climate change on forests of the United States Pacific Northwest. Forest Ecology and Management, 259(4): 720-729.

Maret, M., \& Wilson, M. (2000) Fire and seedling population dynamics in western Oregon prairies. Journal of Vegetation Science, 11: 307-314.

Maret, M., \& Wilson, M. (2005) Fire and litter effects on seedling establishment in western Oregon upland prairies. Restoration Ecology, 13: 562-568.

Memmott, J., \&N. M. Waser. (2002) Integration of Alien Plants into a Native Flower-Pollinator. Proceedings of the Royal Society B: Biological Sciences 269(1508): 2395-2399.

Mote, P, \& Salathé, E. (2010) Future Climate in the Pacific Northwest. Climatic Change, 102(12): $29-50$.

NOAA Climate at a Glance: U.S. Time Series, Average Temperature. National Centers for Environmental Information. (2017).

Oliver, M., Peterson, D., \& Kerns, B. (2016) Predicting the unpredictable: potential climate change impacts on vegetation in the Pacific Northwest. Science Findings, 184: 5.

Peterson, D. W., Kerns, B. K., \& Dodson, E. K. (2014). Climate change effects on vegetation in the Pacific Northwest: A review and synthesis of the scientific literature and simulation model projections. Gen. Tech. Rep. PNWGTR-90o. Portland, OR: US Department of Agriculture, Forest Service, Pacific Northwest Research Station. 183 p., 900.

Pfeifer-Meister, L., Bridgham, S. D., Little, C. J., Reynolds, L. L., Goklany, M. E., \& Johnson, B. R. (2013). Pushing the limit: experimental evidence of climate effects on plant range distributions. Ecology, 94(10), 2131-2137.

Pfeifer-Meister, L., Bridgham, S. D., Reynolds, L. L., Goklany, M. E., Wilson, H. E., Little, C. J., ... \& Johnson, B. R. (2016). Climate change alters plant biogeography in Mediterranean prairies along the West Coast, USA. Global change biology, 22(2), 845-855.

Pfeifer-Meister, L., \& Bridgham, S. (2007) Seasonal and spatial controls over nutrient cycling in a pacific northwest prairie. Ecosystems, 1O(8): 1250-1260.

Price, M., \& Waser, N. (1998) Effects of Experimental Warming on Plant Reproductive Phenology in a Subalpine Meadow. Ecology, 79(4): 1261. 
Rathcke, B. (1983) Competition and Facilitation among Plants for Pollination. Pollination Biology, 305-329.

Reichmann, L., Schwinning, S., Polley, H., \& Fay, P. (2016) Traits of an Invasive Grass Conferring an Early Growth Advantage over Native Grasses. Journal of Plant Ecology 9(6): 672-681.

Reynolds, L., Johnson, B., Pfeifer-Meister, L., \& Bridgham, S. (2015) Soil respiration response to climate change in Pacific Northwest prairies is mediated by a regional Mediterranean climate gradient. Global Change Biology, 21(1): 487-500.

Rook, E., Fischer, D., Seyferth, R., Kirsch, J., LeRoy, C., \& Hamman, S. (2011) Response of Prairie Vegetation to Fire, Herbicide, and Invasive Species Legacy. Northwest Science, 85: 288-302.

Roy, B., Güsewell, S., \& Harte, J. (2004) Response Of Plant Pathogens And Herbivores To A Warming Experiment. Ecology, 85(9): 2570-2581.

Roy, B., \& Mulder, C., (2014) Pathogens, herbivores, and phenotypic plasticity of boreal Vaccinium vitis-idaea experiencing climate change. Ecosphere, 5(3): 1-19.

Salathé, E., Steed, R., Mass, C., \& Kahn, P. (2008) A High-Resolution Climate Model for the U.S. Pacific Northwest: Mesoscale Feedbacks and Local Responses to Climate Change. Journal of Climate, 21: 5708-5726.

Sheehan, T., Bachelet, D., \& Ferschweiler, K. (2015) Projected major fire and vegetation changes in the Pacific Northwest of the conterminous United States under selected CMIP 5 climate futures. Ecological Modelling, 317: 16-29.

Tian, H., Chen, G., Lu, C., Xu, X., Ren, W..., \& Wofsy, S. (2015) Global Methane and nitrous oxide emissions from terrestrial ecosystems due to multiple environmental changes. Ecosystem Health and Sustainability, 1(1): 4.

Vitt, P., Havens, K., Kramer, A., Scollenberger, D., \& Yates, E. (2009) Assisted migration of plants: Changes in latitudes, changes in attitudes. Biological Conservation, 143: 18-27.

Whittington, H., Tilman, D., Wragg, P., \& Powers, J. (2015) Phenological responses of prairie plants vary among species and year in a three-year experimental warming study. Ecosphere, 6(10): 1-15.

Wilson, H., Johnson, B. R., Bohannan, B., Pfeifer-Meister, L., Mueller, R., \& Bridgham, S. D. (2016). Experimental warming decreases arbuscular mycorrhizal fungal colonization in prairie plants along a Mediterranean climate gradient. PeerJ, 4, e2083.

Wu, Z., Dijkstra, P., Koch, G., \& Hungate, B., (2012) Biogeochemical and ecological feedbacks in grassland responses to warming. Nature Climate Change, 2(6): 458-461. 